\title{
Deposition of Titanium Layer on Steel Substrate Using PECVD Method: A Parametric Study
}

\author{
Haman Hedaiatmofidi' ${ }^{1}$, Alireza Sabour Rouh Aghdam', Shahrokh Ahangarani², \\ Mansour Bozorg ${ }^{1}$, Mahboube Azadi ${ }^{1}$, Maryam Valiei ${ }^{3}$ \\ ${ }^{1}$ Surface Engineering Laboratory, Materials Engineering Department, Faculty of Engineering, Tarbiat Modares \\ University, Tehran, Iran \\ ${ }^{2}$ Advanced Materials \& Renewable Energies Department, Iranian Research Organization for Science and Tech- \\ nology, Tehran, Iran \\ ${ }^{3}$ Material Science and Technology, Azad University, Tehran, Iran \\ Email: hedaiatmofidi@yahoo.com, sabour01@modares.ac.ir, sh.ahangarani@gmail.com, \\ Mansour1244@yahoo.com, Mahbub.azadi@gmail.com, a.akbarzadeh@gmail.com
}

Received 9 December 2013; revised 12 January 2014; accepted 26 January 2014

Copyright @ 2014 by authors and Scientific Research Publishing Inc.

This work is licensed under the Creative Commons Attribution International License (CC BY).

http://creativecommons.org/licenses/by/4.0/

(c) (i) Open Access

\section{Abstract}

Metallic titanium film was deposited on $\mathrm{H}-13$ steel substrate at $470^{\circ} \mathrm{C}-530^{\circ} \mathrm{C}$ using plasma enhanced chemical vapor deposition (PECVD) method. In this paper, the effects of manufacturing parameters were investigated on deposited titanium coating characteristics. XRD, FESEM, XPS and AFM were used in order to study coating characteristics. Increasing hydrogen flow rate from 200 to $360 \mathrm{sccm}$, resulted in a $\mathbf{7 2 \%}$ decrease in oxygen content and $38 \%$ decrease in chlorine content of the film. Applied plasma voltage has a severe effect on nanohardness of coating. Pressure of the deposition chamber has a negative effect on titanium characteristics.

\section{Keywords}

PECVD; Titanium Layer; Oxygen Content; XPS

\section{Introduction}

There are varieties of techniques available such as conventional chemical vapor deposition (CVD), physical vapor deposition (PVD) and plasma enhanced chemical vapor deposition (PECVD) to deposit ceramic and metallic coatings. Among these, the latter has some advantages such as low deposition temperature, better adhesion of 
coating to the substrate and uniformity of coating on specimens with complex shapes which makes it unique [1]. PECVD is capable of depositing a uniform and adherent film onto steel at about $500^{\circ} \mathrm{C}$ instead of $1000^{\circ} \mathrm{C}$ in CVD method [2] [3]. Here, metallic characteristics of titanium film were needed [4]-[6], so achieving a metallic and ductile film with low oxygen content was the goal of this research.

Using various techniques lead to distinct morphologies and structures of the coating and as a result mechanical and chemical behavior of coating would be different. Physical methods are mostly used to deposit titanium film [5] [7]-[11]. Different methods such as magnetron sputtering [12]-[16], filtered cathodic arc [17], ion plating [6] [18], plasma immersion ion implantation and deposition [19], hollow cathode deposition [20]-[22], pulsed laser deposition [23], vacuum arc [24], laser ablation [25] [26] were used to deposit titanium layer in different coating systems. Chemical methods are rarely used to deposit titanium film [27]-[31] and yet no research is done about the relation of deposition parameters and characteristics of the layer. Currently there is little information available about using plasma enhanced chemical vapor deposition method and the effect of plasma parameters on coating characteristics. These systematic data is very vital to achieve a coating which satisfies the needs of today's industry. In PECVD method one of most challenging problems is oxygen content of the deposited film due to lower vacuum level in comparison to physical methods. Oxygen content deteriorates metallic characteristics such as ductility and fracture toughness.

In this paper, effects of plasma parameters on coating characteristics were studied in order to deposit a titanium film with optimum condition.

\section{Experimental Method}

H-13 steel samples were prepared in coin like shapes with diameter of $20 \mathrm{~mm}$ and thickness of $5 \mathrm{~mm}$. They were heat treated and their hardness reached $52 \mathrm{HRc}$. Then samples were mechanically polished to the roughness of $0.1 \mu \mathrm{m}$. After that they were degreased and plasma nitrided. The chamber was cylindrical with diameter of 40 $\mathrm{cm}$ and height of $60 \mathrm{Cm}$. The PECVD chamber had a heating system and could raise the temperature of the chamber. The temperature was controlled with a thermocouple placed near the samples in the vacuum chamber. The samples were mounted on the cathode stage and the walls of chamber were connected to earth and acted as anode of the system. The pulsed direct current was used to produce plasma. The power supply was able to produce a voltage up to $700 \mathrm{~V}$ and frequencies up to $12 \mathrm{KHz}$. Flow of gases were controlled by mass flow controllers and $\mathrm{TiCl}_{4}$ was carried to the chamber with $\mathrm{H}_{2}$ as the carrier gas, which flowed through the $\mathrm{TiCl}_{4}$ container at $42^{\circ} \mathrm{C}$. Before starting to enter gasses to chamber, initial pressure reached 0.1 mbar but during the process, chamber pressure was about $4-7$ mbar depending on other parameters. Gas flow rates, plasma voltage and pressure of the chamber were changed to find the parameters which lead to appropriate characteristics of titanium film. Process parameters are shown in Table 1.

Deposition was carried out according to the values given in Table 1 except for the parameter which was under investigation in each step. Temperature of the samples in all experiments was set between $470^{\circ} \mathrm{C}-530^{\circ} \mathrm{C}$. Deposition rates were obtained by measuring coating thickness under FESEM. Surface compositional analysis was done by X-ray photoelectron spectroscopy (PHI 5802) using Al k $\alpha$ monochromatic radiation. Argon gas was used to sputter the surface impurities for 5 minutes. Compositional analysis through depth of titanium layer was also done by argon sputtering.

Nano indentation was done with a Berkovich indenter and a load of $7 \mathrm{mN}$ in order to measure hardness of the coating. For hardness measurement average of three readings is reported and the error of measurement is about 8\% for most of the samples. XRD analysis was done by Expert diffractometer (Philips) with a scan rate of 0.02 degrees per second.

\section{Results and Discussion}

As it is shown in Figure 1, a dense and uniform film containing 11 atomic percent of oxygen is deposited on the substrate. Oxygen is solved in the titanium film according to phase diagram of titanium and oxygen. Compositional analysis also corroborate with SEM micrograph due to formation of a solid solution of titanium and

Table 1. Titanium deposition standard process parameters.

\begin{tabular}{cccccccc}
\hline Pulsed voltage & Duty cycle & Frequency & Pressure & $\mathbf{H}_{\mathbf{2}}$ flow rate & Ar flow rate & $\mathbf{T i C l}_{\mathbf{4}}$ with $\mathbf{H}_{\mathbf{2}}$ carrier & Deposition Time \\
\hline 480 & $33 \%$ & $8 \mathrm{KHz}$ & $4 \mathrm{mbar}$ & $200 \mathrm{sccm}$ & $100 \mathrm{sccm}$ & $13 \mathrm{sccm}$ & $60 \mathrm{~min}$ \\
\hline
\end{tabular}




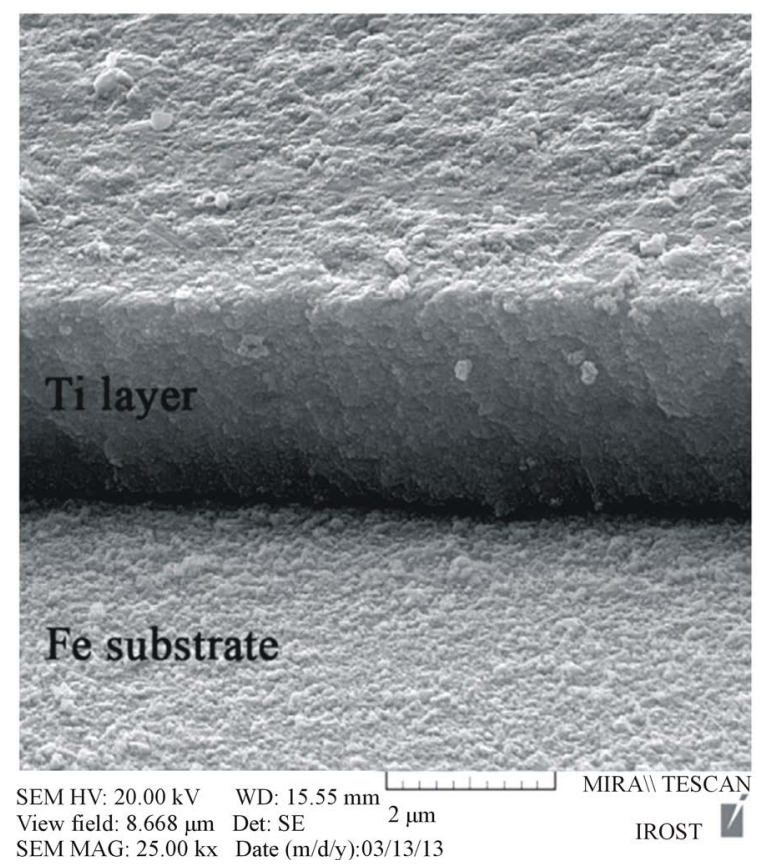

Figure 1. FESEM micrograph of titanium layer deposited on steel.

oxygen. In Figure 2, topology of titanium coating containing 6\% at oxygen is shown. The average crystallite size of samples was between 250 to $400 \mathrm{~nm}$ due to deposition parameters change.

In the following sections the effect of each parameter on coating characteristics is investigated.

\subsection{Voltage}

Voltage is one of the most important parameters which could affect film characteristics. As it is shown in Figure 3 , applying voltage has a drastic effect on hardness of the film. The hardness dependence on the applying voltage can be a result of ion energies and the energy of ion impingement to the surface to create the film. The cathode sheath thickness (dc) multiplied by pressure (p) is a decreasing function as voltage increases [32]. Therefore in constant pressure, dc decreases with increasing the applying voltage, resulting in higher energies of the particles hitting the cathode surface and higher plasma intensity due to higher energies of secondary electrons. This higher energy of ions results in denser and harder coatings. Mogensen et al. [33] found that there is a correlation between deposition rate and hardness of the film. In most of our samples, deposition rate and hardness relationship of the samples corroborates with that result.

\subsection{Pressure}

Plasma intensity decays with the total pressure of deposition. In constant voltage, the cathode-sheath thickness (dc) multiplied by the pressure (p) has approximately a constant value [32], and the mean free path $(\lambda)$ is inversely proportional to the pressure, furthermore the average number of collisions for species travelling across the sheath $(\mathrm{dc} / \lambda)$ is constant. This suggests that the energy distribution of particles hitting the cathode surface is independent of the total pressure. On the other hand as it is shown in Figure 4, increasing total pressure led to increasing oxygen gas in the reacting chamber. Therefore, due to tremendous capability of titanium to dissolve oxygen, higher oxygen in chamber resulted in higher oxygen impurity in the film.

Increasing pressure led to more effective impingement of ions to the cathode surface and as a result increasing the deposition rate of the coating.

\subsection{Argon Flow Rate}

As it is shown in Figure 5, argon flow rate apparently does not have any effect on oxygen impurity. Increasing 

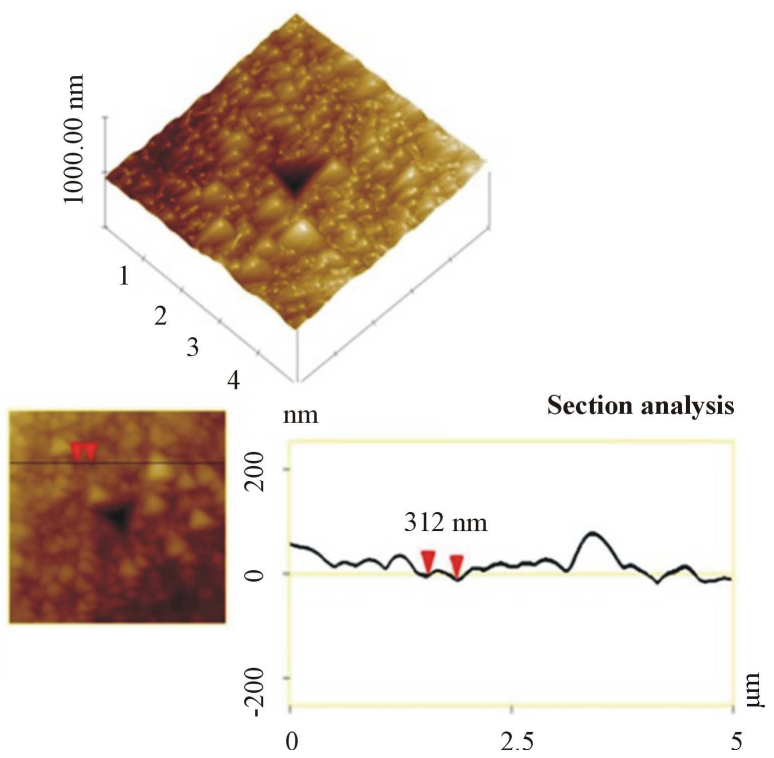

Figure 2. Topology and section analysis of titanium layer.
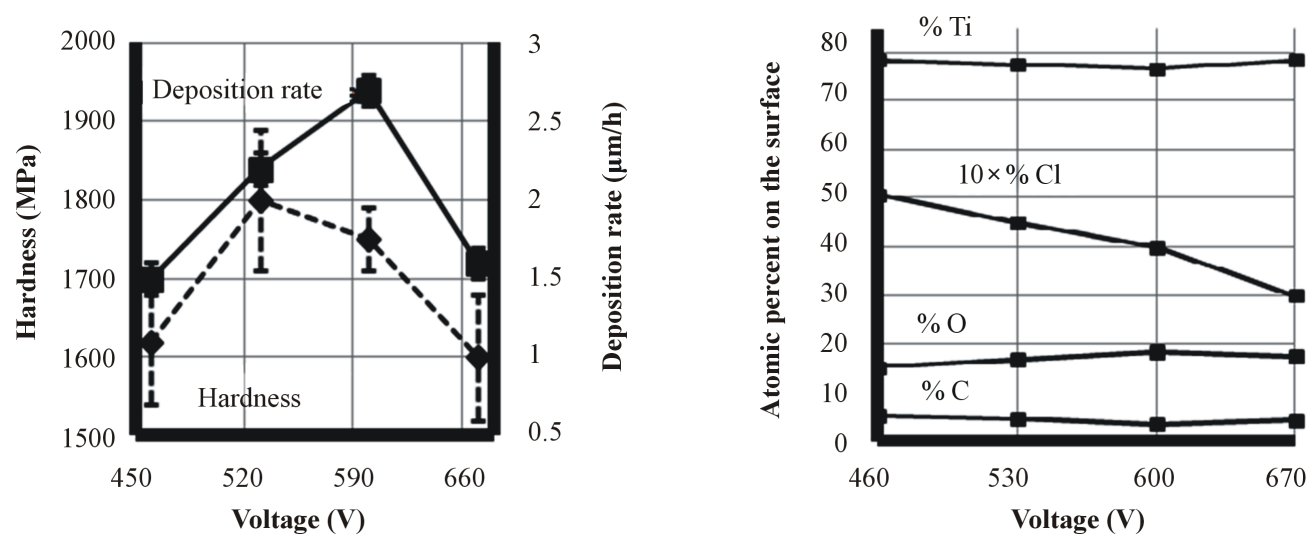

Figure 3. Effect of applying voltage on titanium film characteristics.
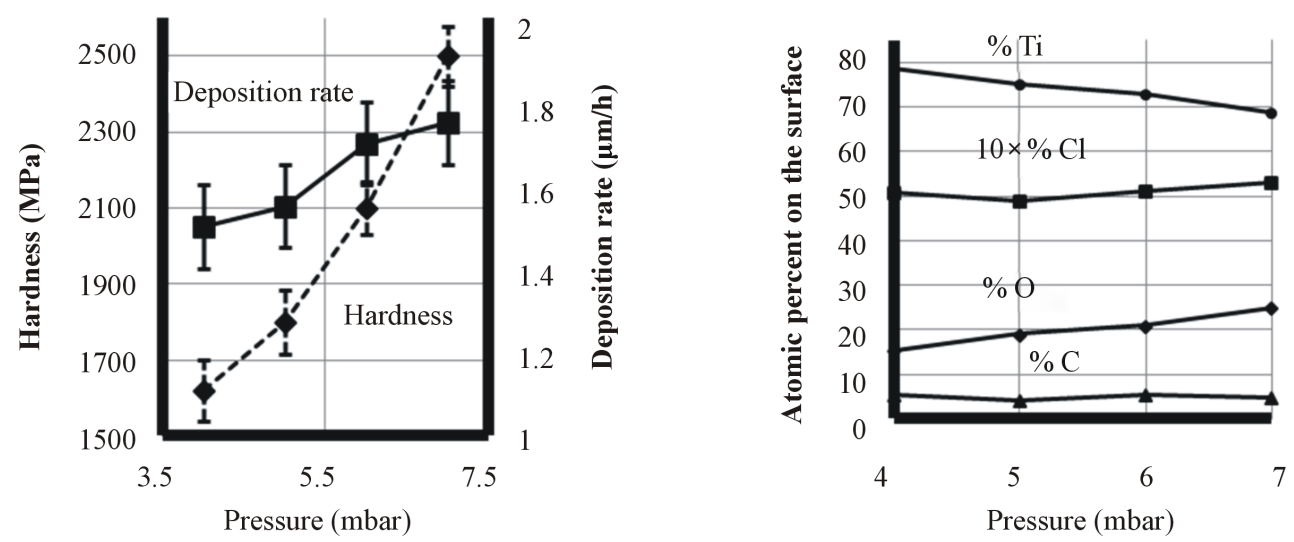

Figure 4. Effect of pressure on titanium film characteristics.

argon flow rates more than $125 \mathrm{sccm}$ resulted in lowering deposition rate, probably due to more severe sputtering which is happening on the surface of the cathode. Increasing argon flow rate from 140 to $160 \mathrm{sccm}$, resulted in decreasing deposition rate, but increasing film hardness. It is probably because of higher compressive residual 
stress created in the film due to higher argon bombardment and also higher argon content which was dissolved in the film.

\subsection{Hydrogen Flow Rate}

Hydrogen is the reduction agent which can control the amount of residual chlorine and oxygen in the chamber as well as the coating. As it is shown in Figure 6, increasing hydrogen flow rate results in an abrupt decrease in oxygen and chlorine impurity in the titanium film, severely decreasing the nanohardness of the film. A correlation between deposition rate and hydrogen flow rate was not seen in this experiment because hardness was severely under the influence of oxygen and chlorine impurity of the film rather the deposition rate. Figure 7 shows XRD peaks of samples deposited under different hydrogen flow rate containing $11 \%, 6 \%$ and $4 \%$ oxygen. In Figures 7(a) and (b), the peaks have a considerable shift to lower angles in comparison to a stress free sample. This peak shift is due to gas impurities which are dissolved in the titanium resulting in a compressive stress. The Figure 7(c) with the lowest oxygen content has the least residual stress and therefore the least peak shift in comparison to other two samples. XPS Surface survey and compositional changes through depth profile of sample coated with hydrogen flow rate of 320 sccm, are shown in Figures 8 and 9, respectively. Impurities concentrations reduce through depth and summation of them reaches to $10 \%$ to $12 \%$. The purity of titanium layer is about $90 \%$ after 500 seconds of sputtering. Using advantages of this metallic layer as Ti/TiN multilayer coating is described elsewhere [34]. Oxygen on the surface is about $6 \%$ but it reduces to $2.7 \%$ after 1000 seconds of sputtering. Carbon impurity dissolved from oil of vacuum pump in the coating and it could not be avoided. There is also chlorine impurity that came from dissociation of precursor titanium chloride.

\section{Conclusion}

Titanium film was deposited on H-13 steel substrate under different process parameters in order to understand the effect of them on the film characteristics and simultaneously obtain the optimum parameters to achieve a
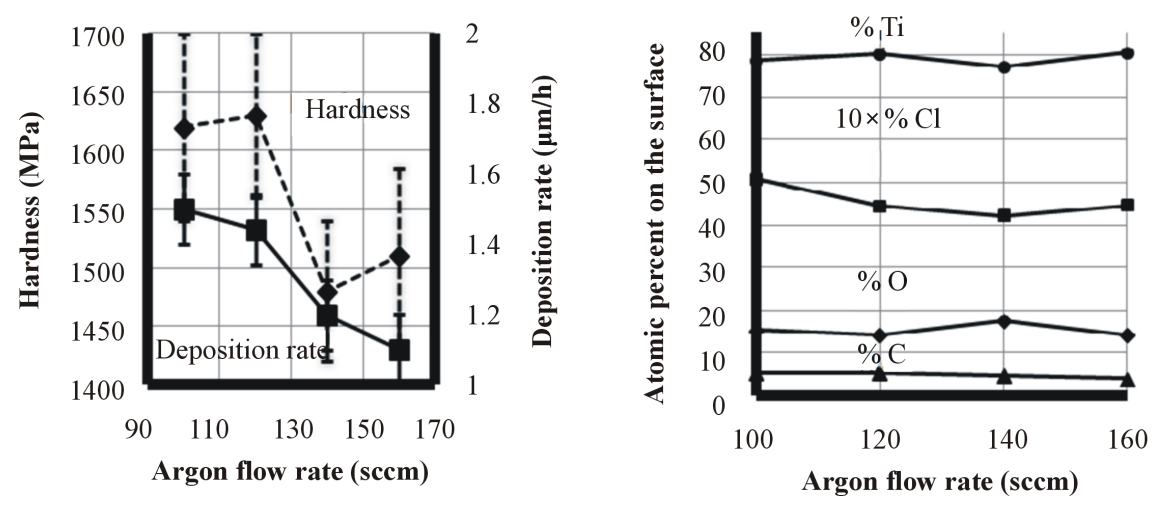

\section{Figure 5. Effect of argon flow rate on titanium film characteristics.}



Hydrogen flow rate (sccm)



Hydrogen flow rate (sccm)

Figure 6. Effect of hydrogen flow rate on titanium film characteristics. 


\section{Titanium layer peaks}

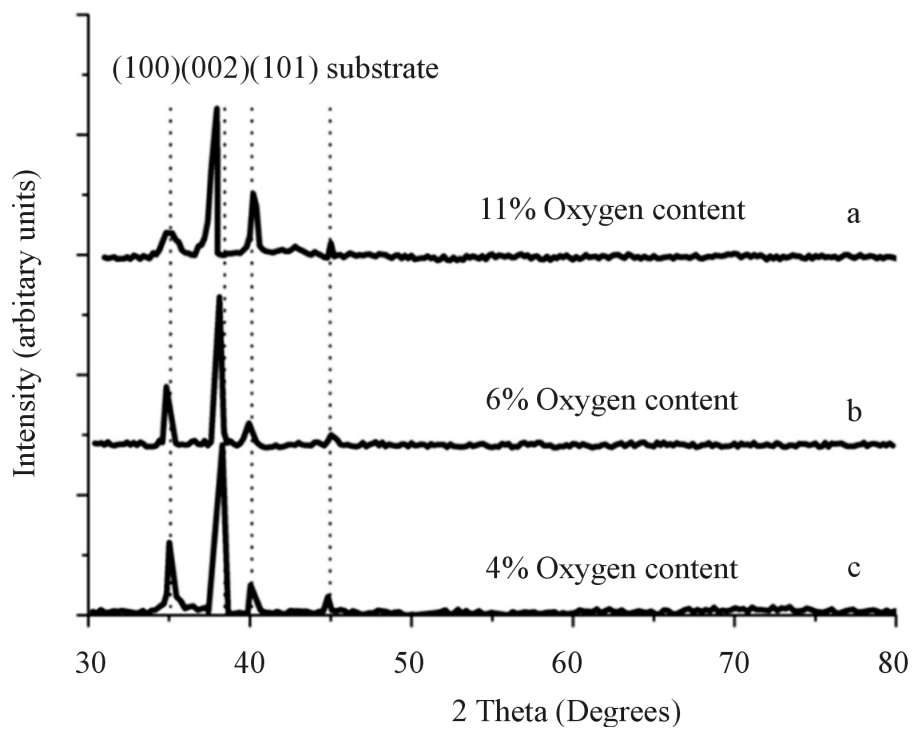

Figure 7. XRD peaks of samples with $11 \%, 6 \%$ and $4 \%$ oxygen content, respectively.
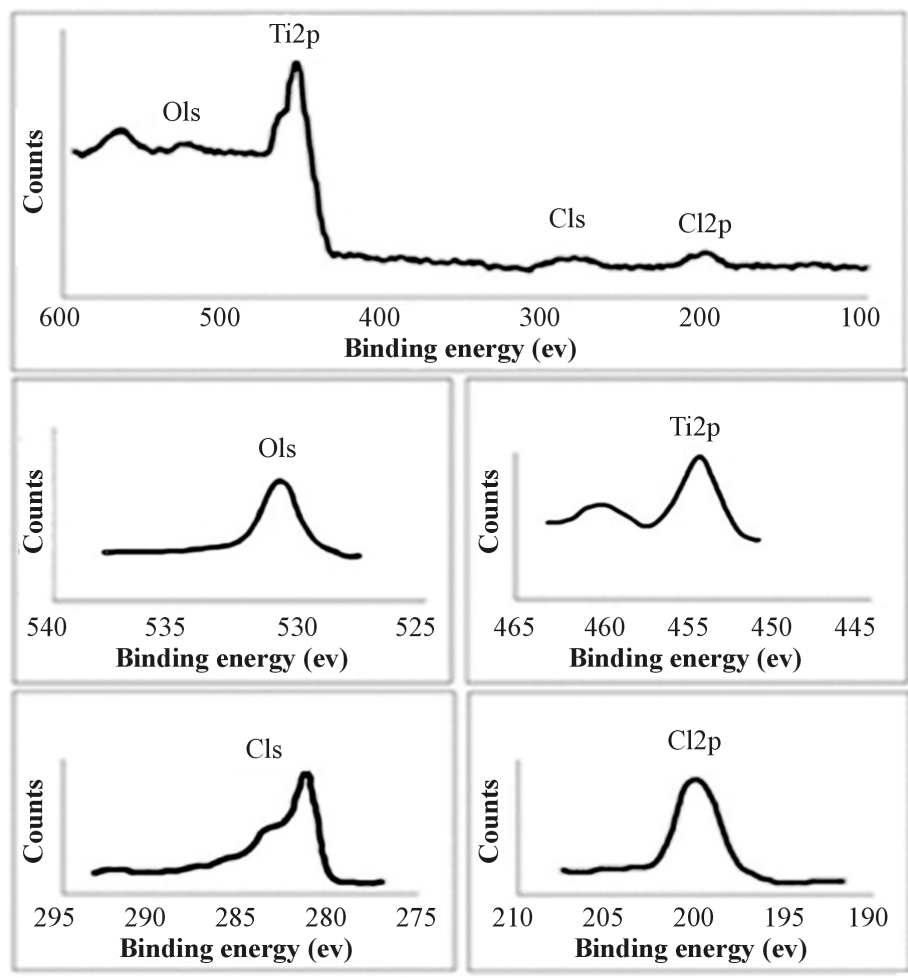

Figure 8. General spectrum and high resolution XPS peaks of sample coated with hydrogen flow of $320 \mathrm{sccm}$.

metallic and ductile film. Increasing pressure of the chamber results in higher oxygen and chlorine contents of the film. Therefore metallic characteristics of the film diminished. On the other hand, increasing hydrogen flow rate, helped to lower oxygen impurity to about $72 \%$. The highest purity of titanium which was achieved in this research was about 90.1 at\% on the surface after 500 seconds of argon sputtering. Applying voltage and argon flow rate was not very effective on controlling gas content of the film but they did have an effect on the deposition 


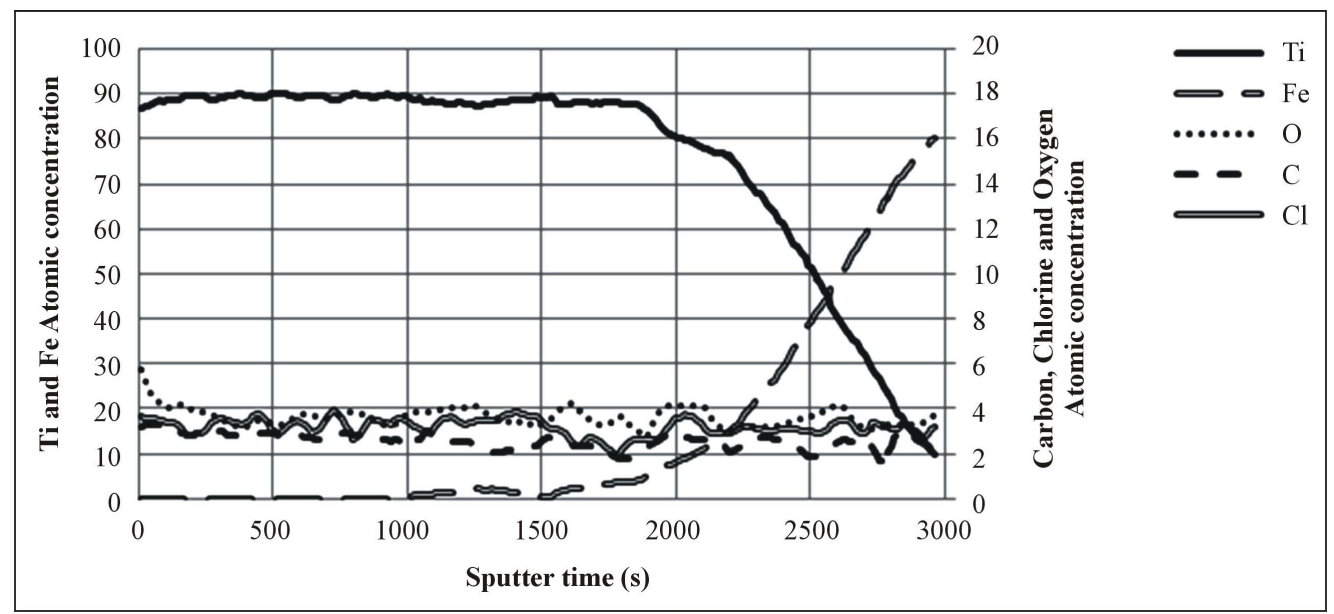

Figure 9. XPS depth profile of elements in sample coated with hydrogen flow rate of $320 \mathrm{sccm}$.

rate. Hardness of the coatings, were dependent mostly on the level of gas impurities dissolved in titanium and deposition rate. In most of the samples, there was a correlation between deposition rate and hardness.

\section{Acknowledgements}

This work was supported by Material Science and Technology Research Center and the Surface Engineering Laboratory, Faculty of Engineering, Tarbiat Modares University.

\section{References}

[1] Kawata, K., Sugimura, H. and Takai, O. (2002) Effects of Chlorine on Tribological Properties of TiN Films Prepared by Pulsed d.c. Plasma-Enhanced Chemical Vapor Deposition. Thin Solid Films, 407, 38-44. http://dx.doi.org/10.1016/S0040-6090(02)00009-3

[2] Thomsen, A.H.N.B., Mogensenc, K.S., Eskildsen, S.S., Mathiasen, C. and Bùttiger, J. (1998) Residual Stress Determination in PECVD TiN Coatings by X-Ray Diffraction: A Parametric Study. Thin Solid Films, 333, 50-59. http://dx.doi.org/10.1016/S0040-6090(98)00804-9

[3] Ma, S.L., Xu, K.W. and Jie, W.Q. (2005) Plasma Nitrided and TiCN Coated AISI H13 Steel by Pulsed dc PECVD and Its Application for Hot-Working Dies. Surface and Coating Technology, 191, 201-205. http://dx.doi.org/10.1016/j.surfcoat.2004.03.048

[4] Bromark, M., Larsson, M., Hedenqvist, P. and Hogmark, S. (1997) Wear of PVD Ti/TiN Multilayer Coatings. Surface and Coatings Technology, 90, 217-223. http://dx.doi.org/10.1016/s0257-8972(96)03141-6

[5] Bemporad, E., Sebastiani, M., Pecchio, C. and De Rossi, S. (2006) High Thickness Ti/TiN Multilayer Thin Coatings for Wear Resistant Applications. Surface and Coatings Technology, 201, 2155-2165. http://dx.doi.org/ 10.1016/j.surfcoat.2006.03.042

[6] Liu, C., Chu, P.K., Lin, G. and Yang, D. (2007) Effects of Ti/TiN Multilayer on Corrosion Resistance of Nickel-Titanium Orthodontic Brackets in Artificial Saliva. Corrosion Science, 49, 3783-3796. http://dx.doi.org/10.1016/j.corsci.2007.03.041

[7] Chang, C.-L., Jao, J.-Y., Ho, W.-Y. and Wang, D.-Y. (2007) Effects of Titanium-Implanted Pre-Treatments on the Residual Stress of TiN Coatings on High-Speed Steel Substrates. Surface and Coatings Technology, 201, 6702-6706. http://dx.doi.org/10.1016/j.surfcoat.2006.09.035

[8] Cubillos, A.D., Parra, E.R., Giraldo, B.S., Arango, Y.C. and Arias Mateus, D.F. (2005) Study of TiN and Ti/TiN Coatings Produced by Pulsed-Arc Discharge. Surface and Coatings Technology, 190, 83-89.

[9] Dück, A., Gamer, N., Gesatzke, W., Griepentrog, M., Österle, W., Sahre, M. and Urban, I. (2001) Ti/TiN Multilayer Coatings: Deposition Technique, Characterization and Mechanical Properties. Surface and Coatings Technology, 142-144, 579-584. http://dx.doi.org/10.1016/j.surfcoat.2004.07.082

[10] Kottfer, D., Ferdinandy, M., Kaczmarek, L., Maňková, I. and Beňo, J. (2013) Investigation of Ti and Cr Based PVD Coatings Deposited onto HSS Co 5 Twist Drills. Applied Surface Science, 282, 770-776. http://dx.doi.org/10.1016/j.apsusc.2013.06.051 
[11] Sobue, S., Yamauchi, T., Suzuki, H., Mukainakano, S., Takenaka, O. and Hattori, T. (1997) Dependence of Diffusion Barrier Properties in Microstructure of Reactively Sputtered TiN Films in Al Alloy/TiN/Ti/Si System. Applied Surface Science, 117-118, 308-311. http://dx.doi.org/10.1016/S0169-4332(97)80099-2

[12] Subramanian, B., Ananthakumar, R., Vidhya, V.S. and Jayachandran, M. (2011) Influence of Substrate Temperature on the Materials Properties of Reactive DC Magnetron Sputtered Ti/TiN Multilayered Thin Films. Materials Science and Engineering: B, 176, 1-7. http://dx.doi.org/10.1016/j.mseb.2010.08.004

[13] Zhang, X.-H. and Liu, D.-X. (2009) Effect of TiN/Ti Multilayer on Fretting Fatigue Resistance of Ti-811 Alloy at Elevated Temperature. Transactions of Nonferrous Metals Society of China, 19, 557-562. http://dx.doi.org/10.1016/S1003-6326(08)60312-X

[14] Caicedo, J.C., Amaya, C., Yate, L., Nos, O., Gomez, M.E. and Prieto, P. (2010) Hard Coating Performance Enhancement by Using [Ti/TiN]n, [Zr/ZrN]n and [TiN/ZrN]n Multilayer System. Materials Science and Engineering: B, 171 56-61. http://dx.doi.org/10.1016/j.mseb.2010.03.069

[15] Saoula, N., Djerourou, S., Yahiaoui, K., Henda, K., Kesri, R., Erasmus, R.M. and Comins, J.D. (2010) Study of the Deposition of Ti/TiN Multilayers by Magnetron Sputtering. Surface and Interface Analysis, 42, 1176-1179. http://dx.doi.org/ 10.1002/sia.3299

[16] Liu, D.G., Tu, J.P., Hong, C.F., Gu, C.D., Mai, Y.J. and Chen, R. (2010) Improving Mechanical Properties of a-CNx Films by Ti-TiN/CNx Gradient Multilayer. Applied Surface Science, 257, 487-494. http://dx.doi.org/10.1016/j.apsusc.2010.07.018

[17] Cheng, Y.H., Browne, T., Heckerman, B., Bowman, C., Gorokhovsky, V. and Meletis, E.I. (2010) Mechanical and Tribological Properties of TiN/Ti Multilayer Coating. Surface and Coatings Technology, 205, 146-151. http://dx.doi.org/10.1016/j.surfcoat.2010.06.023

[18] Zhao, Y., Lin, G., Xiao, J., Du, H., Dong, C. and Gao, L. (2011) Ti/TiN Multilayer Thin Films Deposited by Pulse Biased Arc Ion Plating. Applied Surface Science, 257, 2683-2688. http://dx.doi.org/10.1016/j.apsusc.2010.10.042

[19] Liu, H.X., Jiang, Y.H., Zhou, R. and Tang B.Y. (2012) Wear Behaviour and Rolling Contact Fatigue Life of Ti/TiN/ DLC Multilayer Films Fabricated on Bearing Steel by PIIID. Vacuum, 86, 848-853. http://dx.doi.org/10.1016/j.vacuum.2011.02.015

[20] Zhou, Y., Rao, G.B., Wang, J.Q., Zhang, B., Yu, Z.M., Ke, W. and Han, E.H. (2011) Influence of Ti/TiN Bilayered and Multilayered Films on the Axial Fatigue Performance of Ti46Al8Nb Alloy. Thin Solid Films, 519, 2207-2212. http://dx.doi.org/10.1016/j.tsf.2010.10.025

[21] Huang, R.F., Wen, L.S., Guo, L.P., Gong, J., Yu, B.H. and Bangert, H. (1992) Microstructural and Indentation Characterization of Ti/TiN Multilayer Films. Surface and Coatings Technology, 50, 97-101. http://dx.doi.org/10.1016/0257-8972(92)90049-G

[22] Devia, D.M., Restrepo-Parra, E. and Arango, P.J. (2011) Comparative study of Titanium Carbide and Nitride Coatings Grown by Cathodic Vacuum Arc Technique. Applied Surface Science, 258, 1164-1174. http://dx.doi.org/10.1016/j.apsusc.2011.09.061

[23] Major, L., Morgiel, J., Major, B., Lackner, J.M., Waldhauser, W., Ebner, R., Nistor, L. and Van Tendeloo, G. (2006) Crystallographic Aspects Related to Advanced Tribological Multilayers of $\mathrm{Cr} / \mathrm{CrN}$ and $\mathrm{Ti} / \mathrm{TiN}$ Types Produced by Pulsed Laser Deposition (PLD). Surface and Coatings Technology, 200, 6190-6195. http://dx.doi.org/10.1016/j.surfcoat.2005.11.021

[24] Wu, W.-F., Ou, K.-L., Chou, C.-P. and Hsu, J.-L. (2003) PECVD - Ti / TiNx Barrier with Multilayered Amorphous Structure and High Thermal Stability for Copper Metallization. Electrochemistry Solid State Letter, 6, G27-G29.

[25] Radhakrishnan, G., Adams, P.M. and Speckman, D.M. (2000) Low Temperature Pulsed Laser Deposition of Titanium Carbide on Bearing Steels. Thin Solid Films, 358, 131-138. http://dx.doi.org/10.1016/S0040-6090(99)00681-1

[26] Ali, N., Bashir, S., Ummi, K., Akram, M. and Mahmood, K. (2013) Effect of Dry and Wet Ambient Environment on the Pulsed Laser Ablation of Titanium. Applied Surface Science, 270, 49-57. http://dx.doi.org/10.1016/j.apsusc.2012.12.049

[27] Bull, S.J., Chalker, P.R., Ayres, C.F. and Rickerby, D.S. (1991) The Influence of Titanium Interlayers on the Adhesion of Titanium Nitride Coatings Obtained by Plasma-Assisted Chemical Vapour Deposition. Materials Science and Engineering: A 139, 71-78. http://dx.doi.org/10.1016/0921-5093(91)90599-I

[28] Hu, J.C., Chang, T.C., Chen, L.J., Yang, Y.L. and Chang, C.Y. (1998) Characterization of Multilayered Ti/TiN Films Grown by Chemical Vapor Deposition. Thin Solid Films 332, 423-427. http://dx.doi.org/10.1016/S0040-6090(98)01018-9

[29] Ohshita, Y., Oshida, M., Seki, M. and Watanabe, K. (1998) TiSi2/Si Interface Instability in Plasma-Assisted Chemical Vapor Deposition of Titanium. Journal of Crystal Growth, 193, 322-327. http://dx.doi.org/10.1016/S0022-0248(98)00490-4 
[30] Ruder, A., Grill, A. and Itzhak, D. (1983) Characterization of Titanium Coatings Obtained by the Cold Plasma Technique. Vacuum, 231-233. http://dx.doi.org/10.1016/0042-207X(83)90061-1

[31] Ruder, A. and Itzahk, D. (1982) Titanium Deposition on to Copper Substrates Using the Cold Plasma Technique. Thin Solid Films, 97, 339-343. http://dx.doi.org/10.1016/0040-6090(82)90526-0

[32] von Engel, A. (1983.) Electric Plasma: Their Nature and Uses. Taylor and Francis, London.

[33] Mogensen, N.B.T.K.S., Eskildsen, S.S., Mathiasen, C. and Botiger, J. (1998) A Parametric Study of the Microstructural. Mechanical and Tribological Properties of PACVD TN Coatings. Surface and Coatings Technology, 99, 140-146. http://dx.doi.org/10.1016/0040-6090(82)90526-0

[34] Mofidi, H.H., Rouhaghdam, A.S., Ahangarani, S., Bozorg, M. and Azadi, M. (2013) Fracture Toughness of TiN Coating as a Function of Interlayer Thickness. Advanced Materials Research, 829, 466-470. http://dx.doi.org/10.4028/www.scientific.net/AMR.829.466 